\title{
What Type of Engagement Predicts Success in a Facebook Weight Loss Group?
}

\author{
Sherry Pagoto, PhD \\ University of Massachusetts Medical School \\ Sherry.pagoto@umassmed.edu \\ Danielle E. Jake-Schoffman, PhD \\ University of Massachusetts Medical School \\ Danielle.jakeschoffman@umassmed.edu \\ Zachary Michaels \\ University of Massachusetts Medical School \\ zachary.michaels@umassmed.edu \\ Joseph DiVito \\ University of Massachusetts Medical School \\ joseph.divito@umassmed.edu
}

\begin{abstract}
Studies of social media-delivered behavioral interventions generally reveal that greater engagement is associated with better outcomes. Little is known about whether the type of engagement, volume of content posted, or timing of engagement matters. In the present study, we analyzed whether the content, volume, and timing of participant posts in a Facebook weight loss intervention were associated with weight loss. Findings revealed that reporting a healthy choice, reporting a challenge, and acknowledging other's posts were the most common types of post. Frequency and volume of posts that reported a healthy choice, asked for help, made a plan, responded to weigh ins, acknowledged others, or expressed negative sentiment predicted weight loss, but those that reported a challenge, shared information, expressed support or said something irrelevant did not. Engagement declined by $50 \%$ in the second half of the intervention. Recommendations are made for future research.
\end{abstract}

\section{Introduction}

Recent studies show promise for weight loss interventions delivered via social media platforms (e.g., Facebook).[1-3] Several such studies have reported that engagement, defined as how often a participant reacts and contributes via "likes,"

\author{
Molly E. Waring, PhD \\ University of Massachusetts Medical School \\ Molly.waring@umassmed.edu \\ Jared Goetz \\ University of Massachusetts Medical School \\ jared.goetz@umassmed.edu \\ Jessica Oleski, MA \\ University of Massachusetts Medical School \\ Jessica.oleski@umassmed.edu
}

comments, and posts, is associated with greater weight loss.[3-7] Less is known about whether the specific type of content produced by participants is associated with weight loss.[8] Eliciting participant engagement may be more difficult in social mediadelivered interventions relative to clinic-based programs given that online communication can be accompanied by privacy concerns, discomfort with comments producing a digital footprint,[9] and lack of ability to leverage nonverbal conversational cues such as eye contact. Research that increases our understanding of participant engagement in online groups and its association with weight loss outcomes is needed to inform strategies to improve social media delivered interventions.[10]

Participant engagement varies not only in degree of effort (i.e., hitting "like" button vs writing original posts) but also in content. In our previous work, higher frequency of participant "likes," the lowest effort form of engagement, was associated with greater weight loss.[3] However, higher frequencies of participant posts and replies, which require more effort than simply hitting a "like" button, were not associated with weight loss outcomes. Frequency of posts and replies may be less important than the type and volume of content produced by participants. In the present study, we aim to identify "meaningful engagement," defined as the type of engagement associated with greater weight loss. To this end, one goal of the present study is to characterize the type and volume of content posted by participants. 
Certain types of content produced by participants may be more associated with weight loss than others. For example, participants may generate content that is autobiographical (e.g., "Oh no! Someone brought donuts to work!”), non-autobiographical (e.g., "Check out this chicken recipe"), or off topic (e.g., “Did anyone watch the game last night?”). Autobiographical posts may provide counselors and other group members a window into the participant's progress, the problems they are encountering, and the plans they are making. This may affect how much personalized counseling the participant receives. For example, a participant who frequently shares her/his progress will likely receive more positive reinforcement from the counselor and other group members than one who rarely reports progress. Similarly, a participant who frequently shares problems she/he is having losing weight may be more likely receive guidance on how to overcome those problems than one who does not post about their problems. Further, posting about goals and intentions has an element of accountability that could increase the likelihood of follow through. Nonautobiographical and off topic posts may create fewer opportunities for counseling and support. However, such posts could still strengthen social connection. For example, a post that shares information (e.g., recipes, tips) would not seem to invite personalized counseling although it may be useful for strengthening personal connections via instrumental support. By characterizing the full range of post content we will be able to examine the associations between specific types of content and weight loss.

Higher volume of content produced by a participant (i.e., total character count across all posts and replies) might indicate greater participant investment in the weight loss program and thus be associated with better weight loss outcomes. Facebook has no character limits which allows for the length of posts to vary widely, from single word acknowledgements (e.g., “Thanks!”) to personal narratives (e.g., detailed description of a dietary lapse). Volume of engagement is distinct from frequency of engagement which simply refers to the total number of posts. We will examine whether the total volume of content produced by a participant is associated with greater weight loss and whether this varies by post type.

Finally, the timing of posting behavior may be associated with weight loss outcomes. In traditional programs, group attendance tends to wane toward the end of the program. We examined the association of frequency and volume of posting (and post type) in the first half and second half of the intervention with weight loss outcomes. We hypothesize that more frequent and higher volume posting in the second half of the intervention will be associated with greater weight loss.

In the present study, we aimed to analyze the content and volume of participant posting behavior (i.e., original posts and replies) in a 12-week Facebook-delivered weight loss intervention. Then, we explored how both frequency, total volume, and timing of each type of post was related to percent weight loss at end of treatment. Findings will have implications for how to inform participants on productive ways to engage in online weight loss communities so as to maximize opportunities to receive personalized counseling and support, and ultimately, weight loss outcomes.

\section{Methodology}

\subsection{Recruitment and Screening Procedures}

Participants were recruited from the local community around Worcester, MA as described elsewhere.[3] Inclusion criteria included smartphone users, currently using Facebook, interested in losing weight, and a body mass index (BMI) of 25-45 $\mathrm{kg} / \mathrm{m}^{2}$. Participants were excluded if they had diabetes, were unable to attend assessment visits, had participated in any of our previous weight loss studies, were taking exclusionary medication, had bariatric surgery, had a medical condition that limits physical activity or diet, had no primary care provider, were currently breastfeeding or pregnant, had no scale at home, were in another weight loss program, or did not speak English.

Trial participants $(\mathrm{N}=56)$ were randomly assigned to two conditions. Both conditions received a 12-week Facebook-delivered weight loss intervention but one included 3 participants who received financial compensation to engage daily to role model active engagement and provide social support to other participants. All participants received $\$ 50$ compensation at the follow-up. We previously reported the main results of this study.[3] Because no differences in weight loss, original posts, or replies were observed between the two treatment conditions, we combined conditions for the present study. We also excluded the 3 participants who received financial incentives for engagement, resulting in an analytic sample of 53 participants.

\subsection{Intervention}

Participants received a 12-week Facebookdelivered weight loss intervention based on the 
Diabetes Prevention Program Lifestyle Intervention.[11] Two posts relevant to the topic of the week were made daily (one in the AM and one in the PM), with one coming from each of two counselors' accounts. Then, two weight loss counselors logged in twice daily to reply to participant posts, answer questions, and facilitate conversation. Counselor and participant interactions were asynchronous, meaning no meeting time was required to participate but rather participants could participate whenever convenient, any time of the day or night. Participants received a calorie goal that would facilitate a weekly rate of weight loss of 1-2 pounds and an exercise goal of 175 minutes of moderate intensity physical activity per week. All participants were encouraged to use MyFitnessPal ${ }^{\circledR}$ or similar diet tracking app to help them meet their daily calorie goal. Every Friday a post asked participants to report their weight change over the week (e.g., "lost 1 pound!”) which gave counselors an opportunity to monitor each participant's progress and provide feedback.

\subsection{Measures}

2.3.1. Weight Loss. Baseline and follow-up weights were measured in the lab by research staff using a calibrated balance beam scale. For participants missing weight at follow-up $(n=2)$, we assumed no weight change (baseline value carried forward). Percent weight loss was calculated by dividing pounds lost at follow-up by baseline weight and multiplying by 100 .

2.3.2. Demographics. At baseline, participants reported demographics in survey format.

2.3.3. Post Frequency and Volume. Participants' posts, including original posts and replies to other posts, were extracted from Facebook using Facebook’s Applications Programming Interface (API). Frequency of posts and post type was defined as the total number of original posts and posts in reply made by a participant during the program. Volume of posts and post type was defined as the total character count (spaces included) across all posts (or post type) made by a participant.

\section{Analytic Plan}

We conducted a directed content analysis of participant posts including original posts and posts that were replies to posts by counselors or other participants.[12] Investigators SP and MW reviewed a subset of 50 participant posts and developed an initial codebook of post types. The codebook was iteratively refined by coding three training sets of a $5 \%$ random subsample of posts ( $n=50$ each). After finalizing the codebook, four coders (DJS, JD, JG, ZM) coded all posts with $20 \%$ double-coded. Posts were randomly assigned to coders, stratified by post format (original vs reply) and treatment condition. For replies, posts were randomly assigned to coders such that a coder reviewed all replies to a given post, and coders viewed the conversation thread to aid in coding. Since replies were randomized by parent post, the number of replies per coder varied.

We examined inter-rater reliability by calculating percent agreement and kappa, and discrepantly-coded messages were discussed by the team to reach consensus (72\% agreement, $\kappa=0.61$ [95\% CI: 0.560.67]). Following coding of post type, we categorized each type as autobiographical versus not autobiographical. Autobiographical posts included those disclosing personal details relating to their weight loss journal, while non-autobiographical did not reveal personal details but instead focused on facts or non-personal information.

We summed the number of posts of each type posted by each participant. We calculated the volume of posts as the number of characters including spaces and summing across participants, overall, and by post type. Some participant posts included links to external websites but we removed these URLs from calculations of post volume.

Because frequency and volume variables were not normally distributed, we described distributions with medians and inter-quartile ranges (IQRs) and used Spearman correlations to examine the associations between each post type and percent weight loss. Analyses were conducted using SAS 9.4 (SAS Institute, Inc., Cary, NC).

\section{Results}

Participant characteristics are shown in Table 1.

Table 1: Baseline characteristics of the sample, M (SD) or $\mathrm{n}(\%)$

\begin{tabular}{|l|c|}
\hline & $\mathrm{N}=53$ \\
\hline BMI (kg/m²) & $32.4(4.8)$ \\
\hline Age (years) & $46.2(10.5)$ \\
\hline Female & $48(91 \%)$ \\
\hline Non-Hispanic white & $48(91 \%)$ \\
\hline Married & $35(66 \%)$ \\
\hline$\geq$ Bachelor's degree & $30(57 \%)$ \\
\hline
\end{tabular}

\subsection{Overall participation and weight loss}


Over the 12 weeks, participants lost an average of 2.6\% (SD: 3.5\%). As reported in the main paper,[3] percent weight loss did not differ across conditions with or without superusers included. Over 12 weeks, the 53 participants made a total of 2,918 posts, with a median of 37 (IQR: 16-76; range: 0-262) per participant. Higher post frequency was significantly associated with greater weight loss ( $\mathrm{r}=-0.38$, $\mathrm{p}=0.0052)$.

\subsection{Post Type}

We identified 10 types of participant posts. Table 2 shows frequencies and hypothetical illustrative examples. Report a challenge or slip. In these posts, a participant shared that they have slipped on their diet and/or exercise or have experienced a problem or barrier. Ask for help. In these posts, a participant asks for help, input or advice. If the participant reported a challenge and also asked for help, it was coded as a request for help. Report a healthy choice. In these posts, a participant reported a healthy choice or that she accomplished a goal. If a healthy choice was mentioned along with a slip, it was coded as a healthy choice if the participant ended up in compliance with their calorie goal even when accounting for the slip (e.g., "I ate a cookie at lunch but still met my calorie goal after eating a light dinner!”). It was coded as a slip if the participant seemed behind their goal in spite of a healthy choice (e.g., "I went for a walk, but then ate way too much for dinner!”). Plan/commitment. In these posts, the participant reports a commitment to a healthy behavior or plan. When a post described a healthy choice, a request for help, or a slip along with a commitment, it was coded as a commitment (e.g., "I ate too much this weekend, but this week I will increase my exercise to 6 days!”). Support others. These posts are purely expressions of support to another participant. If content relating to another category is included, the post would be coded in that category. Information. These posts are purely informative and may include links to articles, recipes, or other informative content. Weigh in. In these posts, the participant posts their weight change for the week in response to the Friday weigh-in post. Posts in reply with something other than a weight report were coded according to the content of their reply. Negate. In this type of post, a participant expresses dislike for some aspect of a post or expresses its irrelevance to their situation while offering nothing further. Acknowledgement. These posts affirm, thank, or otherwise acknowledge someone else's post, but provide nothing further that is substantive. Irrelevant. These posts contain content that is irrelevant to the weight loss program.

Table 2: Types of participant posts, proportion of total posts, posts per participant, and illustrative (hypothetical) examples

\begin{tabular}{|c|c|c|c|}
\hline 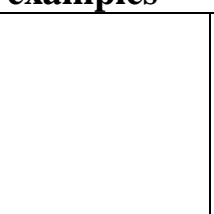 & $\begin{array}{c}\mathrm{N} \\
\text { posts } \\
(\%)\end{array}$ & $\begin{array}{c}\text { Posts } \\
\text { per } \\
\text { person, } \\
\text { median } \\
\text { (IQR) }\end{array}$ & $\begin{array}{c}\text { Illustrative } \\
\text { examples }\end{array}$ \\
\hline \multicolumn{4}{|c|}{ Autobiographical } \\
\hline $\begin{array}{l}\text { Report a } \\
\text { challenge/ } \\
\text { slip }\end{array}$ & $\begin{array}{c}373 \\
(12 . \\
8)\end{array}$ & $\begin{array}{c}4 \\
(2-11)\end{array}$ & $\begin{array}{l}\text { Ate way } \\
\text { too much at } \\
\text { the party! }\end{array}$ \\
\hline Ask for help & $\begin{array}{l}124 \\
(4.3)\end{array}$ & $\begin{array}{c}1 \\
(0-2)\end{array}$ & $\begin{array}{c}\text { I need } \\
\text { ideas for } \\
\text { low cal } \\
\text { snacks. } \\
\end{array}$ \\
\hline $\begin{array}{l}\text { Report a } \\
\text { healthy choice }\end{array}$ & $\begin{array}{c}665 \\
(22 . \\
8)\end{array}$ & $\begin{array}{c}8 \\
(4-18)\end{array}$ & $\begin{array}{c}\text { I just } \\
\text { declined a } \\
\text { donut! Go } \\
\text { me! } \\
\end{array}$ \\
\hline $\begin{array}{l}\text { Making } \\
\text { Plan/Commit- } \\
\text { ment }\end{array}$ & $\begin{array}{c}255 \\
(8.7)\end{array}$ & $\begin{array}{c}4 \\
(1-7)\end{array}$ & $\begin{array}{l}\text { I'm going } \\
\text { to add one } \\
\text { workout } \\
\text { this week. }\end{array}$ \\
\hline Weigh in & $\begin{array}{c}304 \\
(10 . \\
4)\end{array}$ & $\begin{array}{c}6 \\
(1-10)\end{array}$ & $\begin{array}{c}\text { Down } 2 \text { lbs } \\
\text { this week! }\end{array}$ \\
\hline Negate & $\begin{array}{c}31 \\
(1.1)\end{array}$ & $\begin{array}{c}0 \\
(0-1)\end{array}$ & $\begin{array}{c}\text { This recipe } \\
\text { has } \\
\text { broccoli } \\
\text { which I } \\
\text { hate. }\end{array}$ \\
\hline \multicolumn{4}{|c|}{ Non-autobiographical } \\
\hline $\begin{array}{l}\text { Support } \\
\text { others }\end{array}$ & $\begin{array}{l}273 \\
(9.4)\end{array}$ & $\begin{array}{c}2 \\
(1-5)\end{array}$ & $\begin{array}{c}\text { You can do } \\
\text { this! }\end{array}$ \\
\hline Informational & $\begin{array}{l}211 \\
(7.2)\end{array}$ & $\begin{array}{c}2 \\
(1-6)\end{array}$ & $\begin{array}{l}\text { Here's a } \\
\text { great } \\
\text { chicken } \\
\text { recipe! }\end{array}$ \\
\hline $\begin{array}{l}\text { Acknowledge } \\
\text {-ment }\end{array}$ & $\begin{array}{c}608 \\
(20.8)\end{array}$ & $\begin{array}{c}7 \\
(2-19)\end{array}$ & Great post! \\
\hline Irrelevant & $\begin{array}{c}74 \\
(2.5)\end{array}$ & $\begin{array}{c}0 \\
(0-1)\end{array}$ & $\begin{array}{c}\text { Anyone see } \\
\text { the game } \\
\text { last night? }\end{array}$ \\
\hline
\end{tabular}


The three highest frequency post types were Reporting a Healthy Choice, Acknowledgement, and Reporting a Challenge, which accounted for $56.4 \%$ of all posts. The three lowest frequency post types were Negate, Irrelevant, and Ask for Help, which accounted for $7.9 \%$ of all posts. Overall, $60.0 \%$ of participant posts $(n=1752)$ were autobiographical and $40.0 \%(n=1166)$ were non-autobiographical.

\subsection{Post Type and Weight Loss}

Frequencies of 6 of 10 post types were associated with greater percent weight loss (See Table 3). Both higher frequency of autobiographical ( $\mathrm{r}=-0.41$, $\mathrm{p}=0.0025)$ and non-autobiographical ( $\mathrm{r}=-0.30$, $\mathrm{p}=0.0309$ ) posts were associated with greater percent weight loss.

Table 3: Association between post frequency and percent weight loss, by post type

\begin{tabular}{|l|c|c|}
\hline & $\begin{array}{c}\text { Correlation } \\
(\mathrm{r})\end{array}$ & p-value \\
\hline Autobiographical content & 0.1054 \\
\hline $\begin{array}{l}\text { Report a } \\
\text { challenge/slip }\end{array}$ & -0.22 & $0.0278^{*}$ \\
\hline Ask for help & -0.30 & $0.0094^{*}$ \\
\hline $\begin{array}{l}\text { Report a healthy } \\
\text { choice }\end{array}$ & -0.35 & $0.0021^{*}$ \\
\hline $\begin{array}{l}\text { Report Plan/ } \\
\text { Commitment }\end{array}$ & -0.41 & $<0.0001^{*}$ \\
\hline Weigh in & -0.51 & $0.0080^{*}$ \\
\hline Negate & -0.36 & 0.1075 \\
\hline Non-autobiographical content & 0.1258 \\
\hline Support others & -0.22 & $0.0092^{*}$ \\
\hline Informational & -0.21 & 0.2146 \\
\hline Acknowledgement & -0.35 & -0.17 \\
\hline Irrelevant & & \\
\hline *p<.05
\end{tabular}

$* \mathrm{p}<.05$

\subsection{Volume of Posts and Weight Loss}

Overall, participants posted a median of 3,946 (IQR: 1,156-10,426; range: 0-25,773) characters over the 12-week intervention (Table 4). The top three highest volume post types were Report a Healthy Choice, Report a Challenge/Slip, and Acknowledgement, and these accounted for $49.7 \%$ of total volume. The lowest three volume post types were Negate, Irrelevant, and Supporting Others, and these accounted for $6.7 \%$ of total volume. Higher total volume was associated with greater percent weight loss $(r=-0.34, p=0.0137)$. Greater total volume of 6 of 10 post types was associated with greater percent weight loss (See Table 5).

Overall, $71.7 \%$ of post volume was accounted for by autobiographical posts (240,949 characters), and $28.3 \%$ of post volume was accounted for by nonautobiographical posts (95,332 characters). Higher total volume of autobiographical $(r=-0.37$, $\mathrm{p}=0.0069$ ) posts/comments was associated with greater percent weight loss; total volume of nonautobiographical posts/comments was not $(r=-0.25$, $\mathrm{p}=0.0760$ ).

Table 4: Total volume of posts, proportion of total volume, and distribution per participant, by post type

\begin{tabular}{|l|c|c|}
\hline & $\begin{array}{c}\text { Total } \\
\text { volume } \\
(\%)\end{array}$ & $\begin{array}{c}\text { Volume per } \\
\text { participant, } \\
\text { median (IQR) }\end{array}$ \\
\hline Autobiographical content \\
\hline $\begin{array}{l}\text { Report a } \\
\text { challenge/slip }\end{array}$ & $\begin{array}{c}57,721 \\
(17.2)\end{array}$ & $609(207-1639)$ \\
\hline Ask for help & $\begin{array}{c}16,546 \\
(4.9)\end{array}$ & $71(0-353)$ \\
\hline $\begin{array}{l}\text { Report a healthy } \\
\text { choice }\end{array}$ & $\begin{array}{c}107,363 \\
(31.9)\end{array}$ & $985(269-3336)$ \\
\hline $\begin{array}{l}\text { Report } \\
\text { Plan/Commitment }\end{array}$ & $\begin{array}{c}33,826 \\
(10.1)\end{array}$ & $275(30-633)$ \\
\hline Weigh in & $\begin{array}{c}22,887 \\
(6.8)\end{array}$ & $319(20-618)$ \\
\hline Negate & $\begin{array}{c}2,606 \\
(0.8)\end{array}$ & $0(0-17)$ \\
\hline Non-autobiographical content \\
\hline Support others & $\begin{array}{c}14,742 \\
(4.4)\end{array}$ & $130(0-316)$ \\
\hline Informational & $\begin{array}{c}32,389 \\
(9.6)\end{array}$ & $315(0-956)$ \\
\hline Acknowledgement & $\begin{array}{c}43,110 \\
(12.8)\end{array}$ & $388(128-1207)$ \\
\hline Irrelevant & $\begin{array}{c}5,091 \\
(1.5)\end{array}$ & $0(0-55)$ \\
\hline
\end{tabular}

Table 5: Association between volume of posts and percent weight loss, by post type

\begin{tabular}{|l|c|c|}
\hline & $\begin{array}{c}\text { Correlation } \\
(\mathrm{r})\end{array}$ & $\mathrm{p}$-value \\
\hline Autobiographical content & \\
\hline $\begin{array}{l}\text { Report a } \\
\text { challenge/slip }\end{array}$ & -0.19 & 0.1619 \\
\hline Ask for help & -0.38 & $0.0053^{*}$ \\
\hline $\begin{array}{l}\text { Report a healthy } \\
\text { choice }\end{array}$ & -0.34 & $0.0120^{*}$ \\
\hline $\begin{array}{l}\text { Report } \\
\text { Plan/Commitment }\end{array}$ & -0.41 & $0.0024^{*}$ \\
\hline
\end{tabular}




\begin{tabular}{|l|c|c|}
\hline Weigh in & -0.52 & $<0.0001^{*}$ \\
\hline Negate & -0.34 & $0.0128^{*}$ \\
\hline Non-autobiographical content \\
\hline Support others & -0.16 & 0.2632 \\
\hline Informational & -0.25 & 0.0691 \\
\hline Acknowledgement & -0.30 & $0.0267^{*}$ \\
\hline Irrelevant & -0.15 & 0.2729 \\
\hline
\end{tabular}

$* \mathrm{p}<.05$

\subsection{Timing of Posts and Weight Loss}

Approximately two-thirds (65.8\%, $\mathrm{n}=1919)$ of participant posts were made in the first half of the intervention (i.e., first 6 weeks of the 12-week intervention), and one-third in the second half of the intervention (i.e., second 6 weeks of the 12-week intervention; 34.2\%, $\mathrm{n}=999$ ). Participants posted a median of $67 \%$ (IQR: $58-82 \%$; range: $40-100 \%$ ) of their posts in the first half of the intervention, and a median of 33\% (IQR: $18-42 \%$; range: $0-60 \%$ ) in the second half of the intervention. In the first half of the intervention, total post frequency was associated with greater percent weight loss $(\mathrm{r}=-0.34, \mathrm{p}=0.0117)$, as was frequency of autobiographical $(\mathrm{r}=-.0 .33$, $\mathrm{p}=0.0164)$ and non-autobiographical $(\mathrm{r}=-0.29$, $\mathrm{p}=0.0328$ ) posts. Additionally, frequencies of 5 out of 10 post types in the first half of the intervention were associated with greater percent weight (See Table 6). In the second half of the intervention, total post frequency was associated with greater weight loss $(\mathrm{r}=-0.43, \quad \mathrm{p}=0.0015), \quad$ as was frequency of autobiographical $(r=-0.47, p=0.0004)$ and nonautobiographical $\quad(\mathrm{r}=-0.34, \quad \mathrm{p}=0.0130)$ posts. Frequencies of 6 of 10 post types in the second half of the intervention were associated with greater weight loss (See Table 6).

Table 6: Association between number of participant posts and percent weight loss, by post type, in the first and second halves of the intervention

\begin{tabular}{|l|c|c|c|c|}
\hline & \multicolumn{2}{|c|}{$\begin{array}{c}\text { First half of } \\
\text { intervention }\end{array}$} & \multicolumn{2}{c|}{$\begin{array}{c}\text { Second half of } \\
\text { intervention }\end{array}$} \\
\hline & $\mathrm{r}$ & $\mathrm{p}$ & $\mathrm{r}$ & $\mathrm{p}$ \\
\hline Autobiographical content \\
\hline $\begin{array}{l}\text { Report a } \\
\text { challenge/slip }\end{array}$ & -.20 & .1505 & -.26 & .0560 \\
\hline Ask for help & -.30 & $.0319^{*}$ & -.29 & $.0322^{*}$ \\
\hline $\begin{array}{l}\text { Report a healthy } \\
\text { choice }\end{array}$ & -.29 & $.0378^{*}$ & -.47 & $.0004^{*}$ \\
\hline Commitment & -.32 & $.0186^{*}$ & -.47 & $.0004^{*}$ \\
\hline Weigh in & -.43 & $.0011^{*}$ & -.51 & $<.0001^{*}$ \\
\hline Negate & -.26 & .0568 & -.37 & $.0060^{*}$ \\
\hline
\end{tabular}

\begin{tabular}{|l|c|c|c|c|}
\hline \multicolumn{6}{|l|}{ Non-autobiographical content } \\
\hline Support others & -.25 & .0654 & -.11 & .4350 \\
\hline Informational & -.23 & .0926 & -.14 & .3162 \\
\hline $\begin{array}{l}\text { Acknowledge- } \\
\text { ment }\end{array}$ & -.33 & $.0155 *$ & -.39 & $.0044 *$ \\
\hline Irrelevant & -.05 & .7119 & -.17 & .2154 \\
\hline & * $<.05$
\end{tabular}

In terms of total post volume, participants posted a median of 71\% (IQR: $59-88 \%$; range: $25-100 \%$ ) of the total volume of their posts in the first half of the intervention and a median of $29 \%$ of total volume (IQR: $12-41 \%$; range: $0-75 \%$ ) in the second half of the intervention (See Table 7). In the first half of the intervention, total post volume was associated with weight loss $(\mathrm{r}=-0.31, \mathrm{p}=0.0251)$, as was volume of autobiographical posts $(\mathrm{r}=-0.31, \mathrm{p}=0.0245)$. Total volume of non-autobiographical posts was not associated with weight loss in the first half of the intervention $(\mathrm{r}=-0.23, \mathrm{p}=0.0904)$. Additionally, total volume of 6 out of 10 post types in the first half was associated with greater percent weight loss (See Table 7). In the second half of the intervention, total post volume was associated with percent weight loss $(\mathrm{r}=-0.42, \quad \mathrm{p}=0.0018), \quad$ as was volume of autobiographical posts $(\mathrm{r}=-0.44, \mathrm{p}=0.0009)$ and nonautobiographical posts $(r=-0.28, p=0.0403)$. The volumes of 6 out of 10 post types in the second half were associated with greater percent weight loss (See Table 7).

Table 7: Association between volume of participant posts and percent weight loss, by post type, in the first and second halves of the intervention

\begin{tabular}{|l|c|c|c|c|}
\hline & \multicolumn{2}{|c|}{$\begin{array}{c}\text { First half of } \\
\text { intervention }\end{array}$} & \multicolumn{2}{c|}{$\begin{array}{c}\text { Second half } \\
\text { of } \\
\text { intervention }\end{array}$} \\
\hline & $\mathrm{r}$ & $\mathrm{p}$ & $\mathrm{r}$ & $\mathrm{p}$ \\
\hline Autobiographical content \\
\hline $\begin{array}{l}\text { Report a } \\
\text { challenge/slip }\end{array}$ & -.23 & .1035 & -.19 & .1741 \\
\hline Ask for help & -.37 & $.0057^{*}$ & -.30 & $.0282^{*}$ \\
\hline $\begin{array}{l}\text { Report a healthy } \\
\text { choice }\end{array}$ & -.28 & $.0413^{*}$ & -.49 & $.0002^{*}$ \\
\hline Commitment & -.32 & $.0182^{*}$ & -.48 & $.0003^{*}$ \\
\hline Weigh in & -.46 & $.0006^{*}$ & -.50 & $.0002^{*}$ \\
\hline Negate & -.26 & .0599 & -.37 & $.0060^{*}$ \\
\hline Non-autobiographical content & & \\
\hline Support others & -.13 & .3513 & -.20 & .1607 \\
\hline Informational & -.28 & $.0440^{*}$ & -.15 & .2698 \\
\hline Acknowledgement & -.28 & $.0452^{*}$ & -.35 & $.0100^{*}$ \\
\hline Irrelevant & -.09 & .5414 & -.09 & .53578 \\
\hline
\end{tabular}




\section{Discussion}

The present study found that the three most common types of posts in a Facebook-delivered weight loss intervention were Report a Healthy Choice, Acknowledgement, and Report a Challenge/Slip. Negate and Irrelevant posts were the two least common types of posts, suggesting that negative and/or unproductive posts are more the exception than the rule in a coach-guided weight loss community. Ask for Help was also among the 3 least common types of posts, representing less than $5 \%$ of total posts, which may indicate that participants in this setting are not as comfortable asking for help as they are reporting healthy choices or weight loss challenges. Higher frequency and volume of Ask for Help posts were associated with weight loss, suggesting that assertive participants may end up getting the help they need. Requests for help should be encouraged given such posts would seem to more directly elicit counselor and peer coaching than passive reports of successes and challenges.

Findings revealed that higher frequency and volume of all autobiographical posts except Report a Challenge were associated with greater weight loss. When a participant's post reported a challenge but also mentioned a plan or commitment (e.g., "I went over my calorie goal today but am adding a workout this week to help get back on track!”) or asked for help (e.g., "I always overeat on vacations, anyone have any ideas on how to avoid this?”), it was coded according to the latter. Frequency and volume of Plan/Commitment and Ask for Help posts were both associated with greater weight loss which suggests that having a plan or asking for help may be instrumental to how a participant gets through a challenge. Participants who mention their challenges without asking for help or mentioning a plan may need more help problem solving, encouragement, and/or motivation enhancing strategies from coaches. Further research should explore what such individuals would find helpful in those challenging moments and how they would react to unsolicited advice about how to overcome their challenge. Some participants may use such posts to "vent" and are not expecting or wanting unsolicited advice, while others might use such posts as cries for help and would welcome advice. Coaches might respond to such posts by asking what the participant would find helpful in this moment rather than assuming the person is asking for help.
The volume of posts is different from frequency of posting because it reflects how much time a participant has spent making particular types of post. Volume could be impacted by frequency but is also impacted by post length. In the present study we found that participants spent the most time (i.e., highest volume) reporting healthy choices. In fact, as a group, they spent more time reporting healthy choices than the combined time they spent reporting challenges, asking for help, and making plans/commitments. This is consistent with a recent study of the National Cancer Institute's Facebook community for smoking cessation where the most common participant posts were announcing number of days smoke-free.[13] Similarly, a study of a Lose It! Reddit community revealed the most frequently mentioned topic by participants was about a healthy food.[14] Reporting a healthy choice likely receives positive reinforcement in these groups, but it does not necessarily elicit more substantive forms of coaching (e.g., problem solving). Further research should explore what drives reports of healthy choices and how participants would like coaches to respond (e.g., with congratulations, inquiries/suggestions about how to continue the pattern).

Further research should explore what motivates and deters frequency and time spent on each type of post. For example, to what extent are reports of healthy choices driven by peer pressure or social desirability? Is asking for help deterred by feelings of embarrassment or shame? Are participants attempting to garner accountability and/or positive reinforcement by posting their plans/commitments? Do they follow through with the plans they post? Such research would inform how best to elicit certain posting styles and how to balance how much time a participant spends reporting their victories versus asking for help when they need it.

That the frequency and volume of most post types were associated with greater weight loss and none predicted worse weight loss suggests that increasing any engagement the participant feels comfortable with may be useful. In our previous work we discovered that incentivizing some participants to engage frequently doesn't necessarily cue the entire group to engage more. [3] Along with results of the current study, this suggests that future research should explore how to increase engagement in ways that have intrinsic value to the participant. For example, studies could explore what responses participants would like to different forms of engagement. Participants may not be sure what kind of responses to expect to different types of posts they 
make, but they may be more likely to post if they knew specifically what value would come of doing so. Research exploring barriers to engagement might also be useful. Since discomfort engaging online with strangers may be a barrier, allowing participants to invite close ties to online groups may increase their comfort level with engagement.

Nearly two-thirds of participant posts were made during the first half of the intervention and only onethird during the second half, which suggests that efforts are needed to boost engagement over time. Interestingly, many correlations between engagement (frequency and volume) and weight loss were larger in the second half of the intervention than in the first. This was especially true for posts reporting a healthy choice or reporting a commitment/plan. Targeted efforts to increase these types of engagement during the second half of the intervention could prove helpful. The effort required of a participant to engage in an online intervention is far less than it is for a traditional intervention where engagement requires traveling to a 1+ hour clinic visit. Declines in engagement in the online setting then might be more a function of declining motivation and accompanying avoidance behavior more so than participant burden. To the extent that we can encourage participants to post about their declining motivation, we may be able to thwart avoidance behavior and create opportunities for motivational enhancement. Future work should explore factors associated with declining engagement in online interventions to lend insights into how to prevent such declines.

The present study has a number of limitations. The sample size was only 53 and each Facebook group was half that size. Group size may impact engagement thus these results cannot be generalized to larger weight loss groups on Facebook. Another limitation is that the treatment period was only three months which does not capture engagement trends that go beyond 3 months. Another limitation is that many participant posts included content that captured more than one category. We attempted to elucidate the main purpose of the post to fit it into a single category but some richness of the post may have been lost in doing so. This also likely affected inter-rater reliability by forcing coders to decide between two categories in circumstances where the poster may have had more than one purpose. This is the first work to our knowledge that attempted to characterize the purpose of participant posts in this way.

Social media-delivered behavioral interventions allow us to study specific ways participants engage, which has essentially created a science of engagement in behavioral interventions.[10] Our study revealed that most types of engagement are associated with success, but declines in engagement are observed over time. Multivariate and/or cluster analytic approaches to examining the patterns of engagement in larger samples may help us identify specific engagement patterns associated with success. Research is also needed to determine how to increase engagement in these interventions and the type of engagement that will increase participant's receipt of individualized feedback and support.

\section{Acknowledgements}

This work was supported by K24HL124366 to Dr. Pagoto.

\section{References}

[1] Ashrafian H, Toma T, Harling L, Kerr K, Athanasiou T, Darzi A. Social networking strategies that aim to reduce obesity have achieved significant although modest results. Health Aff (Millwood) 2014;33:1641-7.

[2] Willis EA, Szabo-Reed AN, Ptomey LT, et al. Do weight management interventions delivered by online social networks effectively improve body weight, body composition, and chronic disease risk factors? A systematic review. J Telemed Telecare 2016.

[3] Pagoto S WM, Olendzki E, Oleski J, May C, Evans M. The feasibility of incentivizing participation in an online social network weight loss program. . 50th Hawaii International Conference on System Sciences; 2017; Hawaii.

[4] Pagoto SL, Waring ME, Schneider KL, et al. TwitterDelivered Behavioral Weight-Loss Interventions: A Pilot Series. JMIR research protocols 2015;4:e123.

[5] Gold BC, Burke S, Pintauro S, Buzzell P, HarveyBerino J. Weight loss on the web: A pilot study comparing a structured behavioral intervention to a commercial program. Obesity (Silver Spring, Md 2007;15:155-64.

[6] Webber KH, Tate DF, Michael Bowling J. A randomized comparison of two motivationally enhanced Internet behavioral weight loss programs. Behav Res Ther 2008;46:1090-5.

[7] Turner-McGrievy GM, Beets MW, Moore JB, Kaczynski AT, Barr-Anderson DJ, Tate DF. Comparison of traditional versus mobile app self-monitoring of physical activity and dietary intake among overweight adults participating in an mHealth weight loss program. J Am Med Inform Assoc 2013;20:513-8.

[8] Pagoto S, Waring ME, May CN, et al. Adapting Behavioral Interventions for Social Media Delivery. J Med Internet Res 2016;18:e24.

[9] Madden M, Raine L. Americans' Attitudes About Privacy, Security and Surveillance2015. 
[10] Pagoto S, Waring ME. A Call for a Science of Engagement: Comment on Rus and Cameron. Ann Behav Med 2016;50:690-1.

[11] Diabetes Prevention Program Research G. The Diabetes Prevention Program (DPP): description of lifestyle intervention. Diabetes Care 2002;25:2165-71.

[12] Hsieh HF, Shannon SE. Three approaches to qualitative content analysis. Qual Health Res 2005; 15:1277-88.

[13] Cole-Lewis H, Perotte A, Galica K, et al. Social Network Behavior and Engagement Within a Smoking Cessation Facebook Page. J Med Internet Res 2016;18:e205.

[14] Pappa GL, Cunha TO, Bicalho PV, et al. Factors Associated With Weight Change in Online Weight Management Communities: A Case Study in the LoseIt Reddit Community. J Med Internet Res 2017;19:e17.

[15] McCrae RR, Costa Jr PT. A contemplated revision of the NEO Five-Factor Inventory. Personality and Individual Differences 2004;36:587-96. 